\title{
Impact of Transformational Leadership (Idealized Influence, Inspirational Motivation, Intellectual Stimulation, Individualized Consideration) on Employee Performance
}

\author{
Mohammed Matar, Aldhaheri, Mohammed Nussari
}

This study employs structural equations modeling via PLS to analyze the 732 valid questionnaires in order to assess the proposed model that is based on the transformational leadership characteristics to identify its effect on the performance of employees in the government sector in Dubai. The main independent constructs in the model are idealized influence, inspirational motivation, intellectual stimulation, and individualized consideration. The dependent construct is employee performance. The study will describe relations among the various constructs. Our work has improved our insight in the importance of transformational leadership. Results indicated that all four independent variables significantly predicted employee performance with a various percentage. The proposed model explained $37 \%$ of the variance in employee performance.

Keywords: Transformational Leadership; Employee Performance; Dubai.

\section{INTRODUCTION}

L eadership, within the field of academia, appear in a variety of contexts and settings. Ultimately, the concept has been used a large number of times by scholars and practitioners alike in numerous speeches and writings. Despite its wide usage as well as the availability of conceptual suggestions and propositions even theoretically, researchers have still not come to a consensus over its agreed meaning in literature [1]. Varied perspectives exist on whether leadership is a role, function, attribute, or any combination of any of these. Underlying assumptions of leadership models have built on specific leadership behaviors to be used in specific environments of situations.

Due to the current environments that is known to be very competitive and innovative, the link between organizational performance and transformational leadership is never clearer, where competitive advantage is only obtained through innovativeness that enable organizations to improve their outcomes [2, 3]. In such situation, managers must focus in motivating their employees to be part of the innovation

\footnotetext{
Revised Manuscript Received on September 25, 2019

Mohammed Matar, Faculty of Business and Accountancy, Lincoln University College, Selangor, Malaysia

ALDHAHERI, Faculty of Business and Accountancy, Lincoln University College, Selangor, Malaysia

Mohammed NUSSARI, Faculty of Business and Accountancy, Lincoln University College, Selangor, Malaysia
}

processes, and continuously gaining new knowledge that will allow companies to introduce new products into the market [4]. In this point, transformational leadership and human resource practices are seen as a triggers of competence and innovation by recent literature [5]. Further, Heffernan, Harney, Cafferkey, \& Dundon [6] suggested that there is a need for research regarding the variables that mediate between human resource practices and overall performance.

According to Siddique [7], the UAE is among the Middle Eastern nations experiencing a rapid economic development. With the nation undergoing massive growth in numerous sectors, for instance, tourism, trade, and agriculture, most of UAE's organizations have extended in business activities across the world [7]. Moreover, the UAE government vows to enhance its performance according to UAE vision 2021 with leadership being at the core of the strategy [8]. In the current context, the public sector of the UAE has changed in scope over the last few years and continues to implement changes in a manner that is much is similar to the private sector in contemporary times. Turkyilmaz, Akman, Özkan, \& Pastuszak [9] mention that the UAE public sector seeks to offer customer-centric services and is experiencing an ongoing change in various sectors. As a result of this pressure to change, the public-sector organizations have shown an increased interest in adopting transformational leadership that will help achieve results in this regard.

\section{LITERATURE REVIEW}

\section{A. Employee Performance (EP)}

Employee performance is one of the most important variables of management research. It acts as the primmest determining factor for the overall organization performance [10].

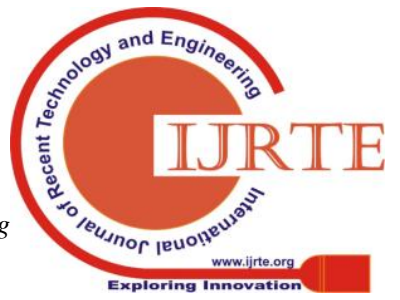


It measures standard or prescribed indicators of the variables like effectiveness, efficiency, and environmental responsibility. Some of the indicators are cycle time, productivity, waste reduction, and regulatory compliance. Employee performance is one of the ultimate dependent variables of researchers' interest in management study. This specific construct allows researchers and managers to evaluate organizations over time with an intention to conduct a comparative analysis with rivals [11]. In short, employee performance is the most important criterion in evaluating organizations, their actions, and environments. It's significance is evident from its usage of employee performance as a dependent variable in previous research studies [11].

\section{B. Transformational Leadership (TL)}

Transformational leadership has been widely accepted as the ideal leadership style in contemporary organizations. This form of leadership has gained recognition because of the remarkable influence of transformational leadership along with its capability to attain the desired organizational outcomes, i.e. employee satisfaction $[12,13]$ and organizational performance [14]. It is widely accepted that transformational leadership has the peculiar ability to instigate higher order need [15]. Aldholay, Isaac, Abdullah, \& Ramayah [16] add that transformational leadership has the ability to motivate employees and generating positive emotions, the creation of an inspirational vision for the vision and directing followers towards achieving these objectives. Drawing on proposed dimensions of transformational leadership by several authors, Aydogdu \& Asikgil [1] derived four dimensions of transformational leadership that were used as fundamental variables for the current research. It includes idealized influence (II), inspirational motivation (IM), Intellectual stimulation (IS) and individualized consideration (IC). Consequently, the following hypotheses are proposed:

H1. II shows a positive impact on employee performance.

H2. IM has a positive effect on employee performance.

H3. IS has a positive effect on employee performance.

H4. IC has a positive effect on employee performance.

Figure 1 shows the proposed study model which contain four independent variables (idealized influence, inspirational motivation, intellectual stimulation, and individualized consideration) and one dependent variable (employee performance).

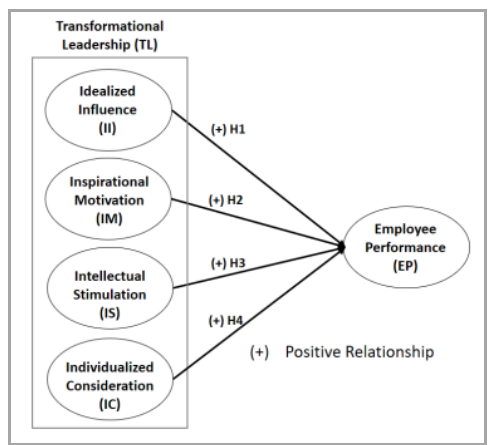

Fig 1: The proposed model

\section{RESEARCH DESIGN AND Methodology}

\section{A. Instrument Development}

The development of an instrument for this study included a 22-item questionnaire, and applied the 5-pointer Likert scale [17] and measured the constructs on the scale of 5 being 'Strongly Agree' and 1 being 'Strongly Disagree'. Given the fact that the respondents were Arabic-speakers, it is required to have the questionnaires translated from English to Arabic in a precise way. Thus, a back translation was applied, which is a procedure widely used in a cross-cultural survey. Previous studies were used to get a validated to measure the variables in this study as shown in Appendix A.

\section{B. Data Collection}

The data was collected by delivering a self-administered questionnaires 'in-person' from April 2018until August 2018 to government employees in Dubai. The number of the questionnaires that were considered suitable for the analysis was 732. According to Tabachnick \& Fidell [19] and Krejcie \& Morgan [20], the sample size was seen as sufficient.

\section{Data Analysis and Results}

SmartPLS 3.0 software was used to analyze the data of this study [21]. A two-stage analytical method [22,23]was used which comprising (i) measurement model assessment and (ii) structural model assessment.

\section{A. Descriptive analysis}

Employee performance score the highest with mean 3.558 out of 5.0, with a standard deviation of 0.942 . Inspirational motivation score the lowest with mean 3.238 out of 5.0, with a standard deviation of 1.049 , as Table 1 shows.

\section{B. Measurement Model Assessment}

The individual Cronbach's alpha, the composite reliability (CR), The average variance extracted (AVE), and the factor loadings exceeded the suggested value [24,25] as illustrated in Table 1. 
Table 1: Measurement assessment results

\begin{tabular}{|c|c|c|c|c|c|c|c|}
\hline Constructs & Item & $\begin{array}{c}\text { Loading } \\
(>0.5)\end{array}$ & M & $\mathrm{SD}$ & $\begin{array}{l}\alpha \\
(>0.7)\end{array}$ & $\begin{array}{c}\text { CR } \\
(>0.7)\end{array}$ & $\begin{array}{c}\text { AVE } \\
(>0.5)\end{array}$ \\
\hline \multirow{4}{*}{$\begin{array}{l}\text { Idealized } \\
\text { Influence } \\
\text { (II) }\end{array}$} & II1 & 0.930 & \multirow{4}{*}{3.405} & \multirow{4}{*}{1.033} & \multirow{4}{*}{0.937} & \multirow{4}{*}{0.955} & \multirow{4}{*}{0.841} \\
\hline & $\mathrm{II} 2$ & 0.918 & & & & & \\
\hline & II3 & 0.907 & & & & & \\
\hline & II4 & 0.914 & & & & & \\
\hline \multirow{4}{*}{$\begin{array}{l}\text { Inspirational } \\
\text { Motivation } \\
\text { (IM) }\end{array}$} & IM1 & 0.929 & \multirow{4}{*}{3.238} & \multirow{4}{*}{1.049} & \multirow{4}{*}{0.945} & \multirow{4}{*}{0.96} & \multirow{4}{*}{0.858} \\
\hline & IM2 & 0.929 & & & & & \\
\hline & IM3 & 0.935 & & & & & \\
\hline & IM4 & 0.912 & & & & & \\
\hline \multirow{4}{*}{$\begin{array}{l}\text { Intellectual } \\
\text { Stimulation } \\
\text { (IS) }\end{array}$} & IS1 & 0.894 & \multirow{4}{*}{3.298} & \multirow{4}{*}{0.996} & \multirow{4}{*}{0.942} & \multirow{4}{*}{0.958} & \multirow{4}{*}{0.851} \\
\hline & IS2 & 0.935 & & & & & \\
\hline & IS3 & 0.942 & & & & & \\
\hline & IS4 & 0.919 & & & & & \\
\hline \multirow{4}{*}{$\begin{array}{c}\text { Individualized } \\
\text { Consideration } \\
\text { (IC) }\end{array}$} & IC1 & 0.943 & \multirow{4}{*}{3.550} & \multirow{4}{*}{1.074} & \multirow{4}{*}{0.948} & \multirow{4}{*}{0.962} & \multirow{4}{*}{0.865} \\
\hline & IC2 & 0.947 & & & & & \\
\hline & IC3 & 0.898 & & & & & \\
\hline & IC4 & 0.932 & & & & & \\
\hline \multirow{6}{*}{$\begin{array}{c}\text { Employee } \\
\text { Performance } \\
\text { (EP) }\end{array}$} & EP1 & 0.916 & \multirow{6}{*}{3.558} & \multirow{6}{*}{1.019} & \multirow{6}{*}{0.942} & \multirow{6}{*}{0.954} & \multirow{6}{*}{0.775} \\
\hline & EP2 & 0.892 & & & & & \\
\hline & EP3 & 0.916 & & & & & \\
\hline & EP4 & 0.823 & & & & & \\
\hline & EP5 & 0.862 & & & & & \\
\hline & EP6 & 0.869 & & & & & \\
\hline
\end{tabular}

The extent that items differentiate among constructs or measure distinct concepts is shown by Discriminant validity. Cross-loadings and Fornell-Larcker were used to assess the discriminant validity of the measurement model. Usually, cross-loadings are used as the first step in testing discriminant validity of the indicators [26]. In the current study, the outer loading of the selected indicators on a construct resulted in all their cross-loadings with remaining constructs. Therefore, the cross loading criterion has been proved to be satisfying the study requirements (refer to Table 2).

Table 2: Cross loading Result

\begin{tabular}{|c|c|c|c|c|c|}
\hline & $I I$ & $I M$ & $I S$ & $I C$ & $E P$ \\
\hline II1 & 0.930 & 0.529 & 0.382 & 0.429 & 0.473 \\
\hline II 2 & 0.918 & 0.500 & 0.364 & 0.378 & 0.411 \\
\hline II3 & 0.907 & 0.513 & 0.378 & 0.364 & 0.413 \\
\hline II4 & 0.914 & 0.538 & 0.411 & 0.445 & 0.416 \\
\hline IM1 & 0.533 & 0.929 & 0.333 & 0.369 & 0.421 \\
\hline IM2 & 0.530 & 0.929 & 0.287 & 0.340 & 0.421 \\
\hline IM3 & 0.543 & 0.935 & 0.319 & 0.363 & 0.445 \\
\hline IM4 & 0.492 & 0.912 & 0.299 & 0.360 & 0.402 \\
\hline IS1 & 0.379 & 0.284 & 0.894 & 0.453 & 0.438 \\
\hline IS2 & 0.386 & 0.312 & 0.935 & 0.529 & 0.435 \\
\hline IS3 & 0.403 & 0.306 & 0.942 & 0.489 & 0.456 \\
\hline IS4 & 0.374 & 0.334 & 0.919 & 0.499 & 0.417 \\
\hline IC1 & 0.429 & 0.406 & 0.520 & 0.943 & 0.467 \\
\hline IC2 & 0.401 & 0.344 & 0.478 & 0.947 & 0.433 \\
\hline IC3 & 0.379 & 0.295 & 0.479 & 0.898 & 0.403 \\
\hline IC4 & 0.430 & 0.386 & 0.508 & 0.932 & 0.404 \\
\hline EP1 & 0.435 & 0.418 & 0.423 & 0.396 & 0.916 \\
\hline EP2 & 0.418 & 0.365 & 0.431 & 0.429 & 0.892 \\
\hline EP3 & 0.412 & 0.383 & 0.420 & 0.419 & 0.916 \\
\hline EP4 & 0.345 & 0.350 & 0.408 & 0.346 & 0.823 \\
\hline EP5 & 0.427 & 0.441 & 0.390 & 0.409 & 0.862 \\
\hline EP6 & 0.429 & 0.445 & 0.431 & 0.426 & 0.869 \\
\hline
\end{tabular}

Table 3 represents the outcome of the analysis of discriminant validity by implementing the Fornell-Larcker criterion. It was found that the square root of the AVEs on the diagonal values are greater than the correlations between constructs (corresponding row 
Impact of Transformational Leadership (Idealized Influence, Inspirational Motivation, Intellectual Stimulation, Individualized Consideration) on Employee Performance

and column values), indicating strong correlation between the constructs and their respective indicators as compared to the other constructs in the model[27,28]. According to Hair et al. [26], this indicates a good discriminant validity.
Furthermore, the exogenous constructs have a correlation of less than 0.85 [29]. Therefore, all constructs had their discriminant validity fulfilled satisfactorily.

\begin{tabular}{|c|c|c|c|c|c|}
\hline & $E P$ & $\overline{I C}$ & $\overline{I I}$ & $I M$ & $I S$ \\
\hline$\overline{\mathrm{EP}}$ & 0.880 & & & & \\
\hline IC & 0.460 & 0.930 & & & \\
\hline II & 0.468 & 0.441 & 0.917 & & \\
\hline IM & 0.456 & 0.386 & 0.567 & 0.926 & \\
\hline IS & 0.474 & 0.534 & 0.418 & 0.334 & 0.923 \\
\hline
\end{tabular}

Note: Diagonals represent the square root of the average variance extracted while the other entries represent the correlations.

\section{Structural Model Assessment}

The structural model can be tested by computing beta $(\beta)$, $\mathrm{R}^{2}$, and the corresponding t-values via a bootstrapping procedure with a resample of 5,000 [23].

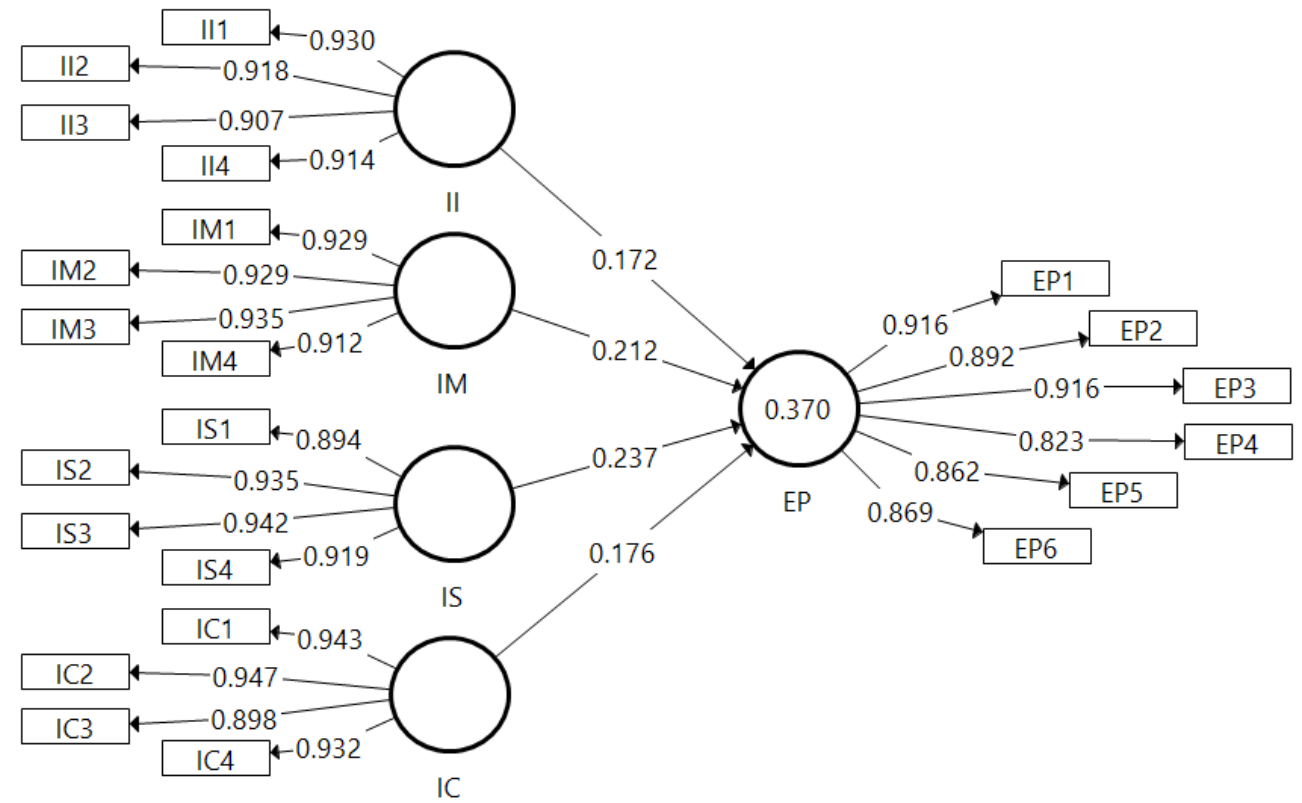

Fig 2: PLS algorithm results

The structural model assessment (Figure 2 and Table 4) shows the hypothesis test results where all the 4 out of 4 hypotheses are supported. II, IM, IS, and IC significantly predict employee performance. Hence, H1, H2, H3 and H4 are accepted with $(\beta=0.172, \mathrm{t}=2.694, \mathrm{p}<0.01)$, $(\beta=0.212, \mathrm{t}=3.152, \mathrm{p}<0.001),(\beta=0.237, \mathrm{t}=4.078, \mathrm{p}$ $<0.001)$, and $(\beta=0.176, \mathrm{t}=2.970, \mathrm{p}<0.01)$, respectively. The relationship between exogenous and endogenous constructs' strength are measured by using the standardized path coefficients. The results show that the direct effect of intellectual stimulation on employee performance is stronger than the influence of other variables.

Thirty-seven percent of the variance in employee performance is explained by II, IM, IS, and IC. The values of $\mathrm{R}^{2}$ have an acceptable level of explanatory power, indicating a substantial model $[28,30]$.

Table 4: Structural assessment results

\begin{tabular}{clllllc}
\hline \hline Hypothesis & Relationship & Std Beta & Std Error & t-value & p-value & Decision \\
\hline H1 & II $\rightarrow$ EP & 0.172 & 0.064 & 2.694 & 0.004 & Supported \\
H2 & IM $\rightarrow$ EP & 0.212 & 0.067 & 3.152 & 0.001 & 0.37 \\
H3 & IS $\rightarrow$ EP & 0.237 & 0.058 & 4.078 & 0.000 & Supported \\
H4 & IC $\rightarrow$ EP & 0.176 & 0.059 & 2.970 & 0.002 & Supported \\
Supported \\
\hline \hline
\end{tabular}




\section{Discussion}

The study found that idealized influence positively affects employee performance in government sector in Dubai, this is supported by previous studies [31,32]. It is explained by the fact that the more government organization leaders give the sense of pride to their subordinates, always put their group before self-interest, act in a way that is being admired, and talking about most important values and beliefs, the higher is staff productivity level, the more the employees are fulfilling their responsibilities, meet all formal performance requirements, complete their duties, and are encouraged to work harder as a result of performance assessment.

Likewise, it was found that Inspirational Motivation positively affects the internal process of organizations among employees in government sector in Dubai, this is supported by previous studies $[1,10]$. It is explained by the fact that the more leaders spread the sense of optimism of the future, and being more enthusiastic about what needs to be accomplished, lay out a vision of the future, and being confident of achieving organizations goals the higher is staff productivity level, the more the employees are fulfilling their responsibilities, meet all formal performance requirements, complete their duties, and are encouraged to work harder as a result of performance assessment.

Additionally, Intellectual Stimulation was found to positively influence internal process of organizations among employees in government sector in Dubai, this is supported by previous studies $([5,33]$. It is explained by the fact that the more leaders tend to re-examine critical assumptions, look for multiple perspectives on problem-solving, and offer new options on how assignment to be completed, the higher is staff productivity level, the more the employees are fulfilling their responsibilities, meet all formal performance requirements, complete their duties, and are encouraged to work harder as a result of performance assessment.

Lastly, the study found that there is a significant relationship between individualized consideration and employee performance, this is supported by previous studies $[5,33]$. It is explained by the fact that the more the leaders treat others as individuals rather than just as a member of a group, consider an individual as having different needs, abilities, and aspirations, seek a different point of view when dealing with organizational issues, help others to develop their strengths, the more the employees are fulfilling their responsibilities, meet all formal performance requirements, complete their duties, and are encouraged to work harder as a result of performance assessment.

\section{IMPLICATIONS, LIMITATIONS AND FUTURE DIRECTIONS}

Employees are the most valuable asset in any organization. Hence, firms should hire talented leaders to provide continuous motivation and inspiration for other employees in their daily operation to attain the organizational goals. Based on the results of this study, transformational leadership is important in terms of II, IM, and IS. The effectiveness of public sector management has always been known to be depended to a certain degree on transformational leadership [15]. Moreover, the results of this study recommend that government sectors should take essential measures to increase the commitment level of the employees in the organization with a focus on the leadership role, policies and work conditions [13]. The results also show that public organization should have the suitable person for the suitable job and provide the employees with the appropriate training to enhance their performance and skills. Further, managers should provide strong leadership and mentoring for employees as well as other working conditions that would encourage and challenge. All these would lead to develop the employee's performance.

With regard to limitations, sample size is considered. The sample of the study includes only one organization of the government sector in the UAE. The research could have been implemented in multiple organizations to address its impact on the transformational leadership on employee performances. Future work may include a various sample from multiple sectors, perhaps from several areas to see the impact of transformational leadership dimensions on the constructs that are investigated [16].

\section{CONClusion}

While the United Arab Emirates government institutions are a pioneer of in the region in terms of performance, it is determined to improve its public organizations' efficiency [34]. This study aims at identifying the aspects that influence employee performance in the government sector in Dubai. The study results were promising irrespective of several constraints to it as it has managed to highlight a new area of knowledge. The proposed model in this study includes four dimensions of transformational leadership (inspirational motivation, idealized influence, individualized consideration, and intellectual stimulation) as independent variables and employee performance as the dependent variable. The results revealed that the four hypotheses are significant. The independent variables significantly explain $37 \%$ of employee performance.

\section{APPENDIX}

Appendix A

Instrument for varibles 
Impact of Transformational Leadership (Idealized Influence, Inspirational Motivation, Intellectual Stimulation, Individualized Consideration) on Employee Performance

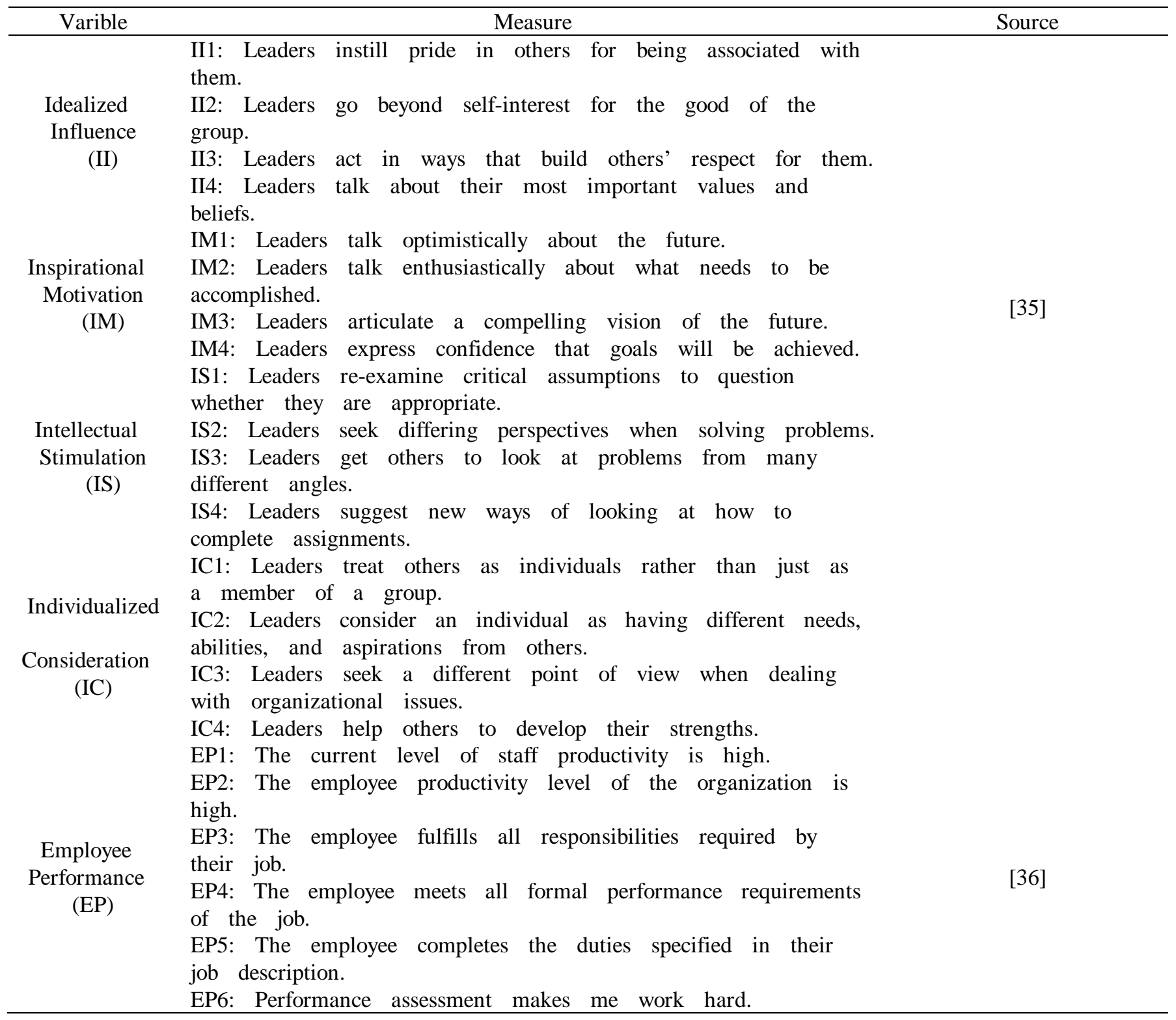

\section{REFERENCES}

1. S. Aydogdu \& B. Asikgil, (2011). The Effect of Transformational Leadership Behavior on Organizational Culture: An Application in Pharmaceutical Industry. International Review of Management and Marketing, 1(4), pp. 65-73.

2. J. A. Aragón-Correa, V. J. García-Morales \& E. Cordón-Pozo, (2007). Leadership and organizational learning's role on innovation and performance: Lessons from Spain. Industrial Marketing Management, 36(3), pp. 349-359. https://doi.org/10.1016/j.indmarman.2005.09.006

3. M. J. Donate \& J. D. Sánchez de Pablo, (2015). The role of knowledge-oriented leadership in knowledge management practices and innovation. Journal of Business Research, 68(2), pp. 360-370. https://doi.org/10.1016/j.jbusres.2014.06.022

4. C. Andriopoulos \& M. W. Lewis (2010). Managing Innovation Paradoxes: Ambidexterity Lessons from Leading Product Design Companies. Long Range Planning, 43(1), pp. 104-122. https://doi.org/10.1016/j.lrp.2009.08.003

5. M. Afacan Findiklı, U. Yozgat \& Y. Rofcanin (2015). Examining Organizational Innovation and Knowledge Management Capacity The Central Role of Strategic Human Resources Practices (SHRPs). Procedia - Social and Behavioral Sciences, 181, pp. 377-387. https://doi.org/10.1016/j.sbspro.2015.04.900

6. M. Heffernan, B. Harney, K. Cafferkey \& T. Dundon, (2016). Exploring the HRM-performance relationship: the role of creativity climate and strategy. Employee Relations, 38(3), pp. 438-462. https://doi.org/10.1108/ER-06-2015-0110
7. M. Siddique, (2012). Knowledge management initiatives in the United Arab Emirates: a baseline study. Journal of Knowledge Management, 16(5), pp. 702-723. https://doi.org/10.1108/13673271211262763

8. M. Mathias, (2017). Public leadership in the United Arab Emirates: towards a research agenda. International Journal of Public Sector Management, 30(2), pp. 154-169. https://doi.org/10.1108/IJPSM-09-2016-0151

9. A. Turkyilmaz, G. Akman, C. Özkan \& Z. Pastuszak, (2011). Empirical Study of Public Sector Employee Loyalty and Satisfaction. Industrial Management and Data Systems, 111.

10. C. Gavrea, L. Ilies \& R. Stegerean, (2011). Determinants of organizational performance: The case of Romania. Management \& Marketing, 6(2), pp. 285-300

11. P. J. Richard, T. Devinney, G. Yip \& G. Johnson, (2009). Measuring Organizational Performance: Towards Methodological Best Practice. Journal of Management $\quad$ Vol. https://doi.org/10.1177/0149206308330560

12. Ngadiman, A. Eliyana \& D. Ratmawati, (2013). Influence of Transformational Leadership and Organization Climate to the Work Satisfaction , Organizational Commitment and Organizational Citizenship Behavior on the Educational Personnel of. European Journal of Business and Management, 5(10), pp. 97-115.

13. M. L. Voon, L. May-Chiun, K. S. Ngui \& N. Ayob, (2011). The Influence of Leadership Styles on Employees 'Job Satisfaction in Public Sector Organizations in Malaysia. International Journal of Business, Management and Social Sciences, 2(1), pp. 24-32. 
14. G. Wang, I.-S. Oh, S. H. Courtright \& A. E. Colbert, (2011). Transformational Leadership and Performance Across Criteria and Levels: A Meta-Analytic Review of 25 Years of Research. Group \& Organization Management, 36(2), pp. 223-270. https://doi.org/10.1177/1059601111401017.

15. J. Rowold \& W. Schlotz, (2009). Transformational and transactional leadership and followers' chronic stress. Leadership Review, 9(1), pp. 35-48.

16. A. H. Aldholay, O. Isaac, Z. Abdullah, I. Alrajawy \& M. Nusari (2018). The Role of Compatibility as A Moderating Variable in The Information System Success Model: The Context of Online Learning Usage. International Journal of Management and Human Science (IJMHS), 2(1), pp. $9-15$.

17. B. C. Lee, J. O. Yoon \& I. Lee, (2009). Learners' acceptance of e-learning in South Korea: Theories and results. Computers and Education, 53(4), pp. 1320-1329. https://doi.org/10.1016/j.compedu.2009.06.014

18. R. W. Brislin (1970). Back-Translation for Cross-Cultural Research. Journal of Cross-Cultural Psychology Vol. 1. Brislin. https://doi.org/10.1177/135910457000100301

19. B. G. Tabachnick, \& L. S. Fidell, (2012). Using Multivariate Statistics (6th ed.). Pearson.

20. R. V Krejcie \& D. W. Morgan, (1970). Determining sample size for research activities. Educational and Psychological Measurement, 38, pp. 607-610.

21. C. M. Ringle, S. Wende \& J.-M. Becker (2015). SmartPLS 3. Bonningstedt: SmartPLS.

22. J. C. Anderson \& D. W. Gerbing, (1988). Structural Equation Modeling in Practice: A Review and Recommended Two-Step Approach. Psychological Bulletin, 103(3), pp. 411-423.

23. J. F. Hair, G. T. M. Hult, C. Ringle \& Sarstedt, M. (2017). A Primer on Partial Least Squares Structural Equation Modeling (PLS-SEM) (2nd ed.). London: Thousand Oaks: SAGE.

24. (R. B. Kline, (2010). Principles and practice of structural equation modeling (3rd ed.). New York: The Guilford Press.

25. J. F. Hair, W. C. Black, B. J. Babin \& R. E. Anderson, (2010). Multivariate Data Analysis (7th ed.). New Jersey: Pearson.

26. J. F. Hair, G. T. M. Hult, C. Ringle \& Sarstedt, M. (2017). A Primer on Partial Least Squares Structural Equation Modeling (PLS-SEM) (2nd ed.). London: Thousand Oaks: SAGE.

27. C. Fornell \& D. F. Larcker, (1981). Evaluating structural equation models with unobservable variables and measurement error. Journal of Marketing Research, 18(1), pp. 39-50.

28. W. W. Chin, (1998a). Issues and opinion on structural equation modeling. MIS Quarterly, 22(1), pp. 7-16.

29. Z. Awang, (2014). Structural Equation Modeling Using AMOS. Shah Alam.Malaysia: University Teknologi MARA Publication Center.

30. J. Cohen (1988). Statistical Power Analysis for the Behavioral Sciences (2nd ed.). London: Routledge. 